News \& Views

\title{
A systematic network-based migratory bird monitoring and protection system is needed in China
}

\author{
Yali Si ${ }^{\mathrm{a}, \mathrm{b}}$, Fei Xu ${ }^{\mathrm{a}}$, Jie Wei ${ }^{\mathrm{a}}$, Lin Zhang ${ }^{\mathrm{a}}$, Nicholas Murray ${ }^{\mathrm{c}}$, Rui Yang ${ }^{\mathrm{d}}$, Keping Ma ${ }^{\mathrm{e}}$, Peng Gong ${ }^{\mathrm{a}, \mathrm{d}, *}$ \\ ${ }^{a}$ Ministry of Education Field Research Station for East Asian Migratory Birds, Department of Earth System Science, Tsinghua University, Beijing 100086, China \\ ${ }^{\mathrm{b}}$ Institute of Environmental Sciences, Leiden University, Leiden 2311 CT, the Netherlands

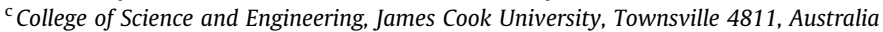 \\ ${ }^{\mathrm{d}}$ Institute for National Parks, Tsinghua University, Beijing 100086, China \\ e Institute of Botany, Chinese Academy of Sciences, Beijing 100093, China
}

The East Asian-Australasian Flyway (EAAF) is the most threatened flyway worldwide, encompassing the greatest number of threatened migratory bird species of all flyways on Earth [1]. This is largely attributed to pronounced human-bird conflicts in Asia, leading to elevated rates of habitat loss, degradation, and illegal hunting $[2,3]$. During the last few decades, there was extensive degradation of Asia's inland [4] and coastal wetlands [5], vital habitats used by migratory species during their annual migration, spanning from Arctic Russia and Alaska to the southern limits of Australia and New Zealand. The impact of this widespread habitat loss is becoming increasingly obvious. Over half of the critical sites of a globally threatened waterfowl species experienced habitat loss [6] and, as tidal mudflat habitats in the Yellow Sea shrank, populations of migratory shorebirds that rely on this region showed rapid population declines [7]. The loss of migratory species diversity can lower the diversity and stability of ecological communities globally, leading to subsequent declines in ecosystem functioning and ecosystem stability [8]. Since China has undergone fast economic growth and rapid urbanization, unprecedented in human history [3], the strategy of China in safeguarding the massive migration of wild birds along the world's most populated and threatened flyway should be examined in more detail. Here, we present an analysis of a globally-recognized important bird area network defined by BirdLife International [9] to investigate: (1) China's potential role in the protection of the EAAF, (2) the shortfalls of migratory bird surveillance and conservation in China, and (3) the path ahead for the migratory species conservation policies in China.

A network of well-connected sites has a positive effect on the persistence of migratory species by facilitating long-distance movements that enable individuals to complete their full annual cycle [10]. The Convention on Biological Diversity (CBD) Aichi target 11 , as well as the draft Post-2020 Global Biodiversity Framework targets, aim to expand protected area networks, while simultaneously improving network connectivity. More than onefifth $(21 \%)$ of important bird areas along the EAAF, identified using an internationally agreed set of criteria as being globally important

\footnotetext{
* Corresponding author.

E-mail address: penggong@tsinghua.edu.cn (P. Gong).
}

for the conservation of bird populations, are in China (Fig. S1a online). Among a large number of areas (over 70\%) that are only partially protected or not at all (Fig. S1b online), China has the greatest proportion of unprotected important bird areas (27\%) of any country in the flyway.

Using important bird areas as nodes and the connections between them as edges, we estimate the functional connectivity [11] (Supplementary materials online) of this habitat network in facilitating bird movement. The potential contribution of each country is evaluated based on the net increase of functional connectivity, by adding partially and unprotected areas in a country to the network of already protected areas. We find that China ranks the first in the potential contribution to the network connectivity (Fig. S1c, Table S1 online), accounting for $156 \%$ of potential connectivity increase, followed by Russia (120\%) and Japan (114\%). With the greatest proportion of partially/unprotected important bird areas in the flyway, but the highest potential contribution of any country, China has a critical role to play in enhancing protection and safeguarding the future of the flyway.

Understanding long-term bird population dynamics and habitat status is crucial to develop nation-wide conservation plans. However, in China, there is a mismatch between the established field monitoring network and the important bird area network. China has established a bird diversity observation network, the China Biodiversity Observation Network-Birds (China BON-Birds) project, and three sets of ecosystem-based monitoring stations designated by different governmental agencies (Fig. S2 online). China BONBirds was initiated in 2011, and consists of 338 observation sites (with 321 located in the EAAF) as of 2016 [12]. Yet only 193 of these were established near important bird areas (within $50 \mathrm{~km}$ ), limiting on-ground monitoring of birds to only $37 \%$ of important bird areas in China (Fig. S2a online). The other three types of stations are not specifically designed for bird monitoring, but for monitoring ecosystems such as wetlands, lakes, and agricultural areas. The overlap of stations located in the EAAF with important bird area is limited, with only 66 out of 141 stations issued by the Forest Bureau (Fig. S2b online), 17 out of 47 stations issued by the Ministry of Science and Technology (Fig. S2c online), and 15 out of 24 stations issued by the Ministry of Educations of China 
(Fig. S2d online) near these areas. Another parallel biodiversity monitoring and research network (China Biodiversity Observation and Research Network, Sino BON), initiated by the Chinese Academy of Sciences in 2013, is still under development [13].

Besides this spatial mismatch, China (as well as other Asian countries) lacks long-term data on bird observations. Long-term data is critical for understanding the impact of global environmental change on migratory species and could be used for generating effective conservation measures. Some countries, such as Australia, have conducted systematic bird counts at important sites since the early 1980 s and listed threatened species in legislation. However, long-term bird surveys, population trends, and habitat assessments are largely missing in China (except for a few sites along the coast). For example, even for the critically endangered Siberian crane (Grus leucogeranus), wintering at Poyang Lake, there was only intermittent survey data. Filling the monitoring gap are local birdwatching societies and birdwatchers, who have gradually developed a long-term online bird monitoring dataset. Individual institutions, such as the National Bird Banding Centre, and the Science Unit in the East Asian-Australasian Flyway Partnership (EAAFP), are also coordinating efforts to monitor species along the Chinese coastline.

China has made substantial progress in conservation in the past few decades. Over 2600 natural reserves had been established by 2014 , covering approximately $10 \%$ of China's land area [14]. In 2011, China developed the Biodiversity Conservation Strategy and Action Plan 2011-2030, and then proposed the Ecological Protection Red Line (EPRL) in 2013 to protect core ecological zones and areas with high vulnerability. In 2019, some coastal wetlands important for migratory birds, like Yancheng, have been designated as The United Nations Educational, Scientific and Cultural Organization (UNESCO) World Heritage Sites. That same year the National Forestry and Grassland Administration of China undertook a process to review and revise the protected species list. More important sites critical for migratory birds have been identified with satellite tracking efforts and improved field surveys. In 2021, the delayed 15th Conference of the Parties to the Convention on Biological Diversity (COP15) is scheduled to be held in China for the first time, providing a unique opportunity to strengthen migratory bird conservation in China.

We suggest improving the conservation of migratory birds through network-based bird monitoring and protection strategies. Tracking habitat protection performance and monitoring bird populations are necessary. A targeted and sustained financial investment is essential to implement these strategies. However, in the most recent field observation station selection criteria announced by the Ministry of Science and Technology, no plan for the protection of migratory birds was included. In addition, China is in the process of developing its protected area system. It is important to ensure habitat network connectivity (i.e., protecting sites that contribute critically to the network connectivity) will be addressed in any system planning.

According to the China National Population Development Plan (2016-2030), 200 million people are expected to migrate from rural to urban areas, mainly in eastern China. This region is forecast to undergo a rapid urban expansion by 2030 [15]. This huge migration of humans in eastern China will put extreme pressure on important bird habitats located in this region. These partially and unprotected critical sites that contribute most to the network connectivity should be quickly converted to protected bird refuges. For those that cannot be readily converted to protected areas, creating temporary habitats when and where migratory birds are present could be a solution. Co-management of natural resources by local communities and the government (e.g., developing ecotourism) has proven effective in areas where human-bird interaction is high. Clearly, strengthening China's legislation to protect bird migration is needed. In 1988, China passed the Wildlife Protection Law of China, and the protection of migratory species and their migration corridor were only included for the first time in the 2018 revision. Continuing the strengthening of China's other legislation to protect bird migration is also important. For example, The China National Park Law, currently under development, should explicitly incorporate the protection of migratory species and their habitats.

To reflect China's irreplaceable role in linking the EAAF's connected habitat network, China should take more actions. For example, strengthening the efforts in bilateral migratory bird agreements (e.g., China-Russia Migratory Bird Agreement and the Ramsar Convention), helping achieve the proposed objectives in the EAAFP strategic plan 2019-2028, and putting open scientific data policy into practice.

China has successfully downlisted the threatened status of the giant panda after decades of intensive government and public engagement and coordinated network protection. The implications are clear: owing to the potential gains that we have shown China could make by targeted protection of migratory birds, China is in a position to make a sustained and positive impact on the EAAF. The benefits of these actions in China would spill over to the other 27 countries that are included in one of the largest bird migrations on the planet.

\section{Conflict of interest}

The authors declare that they have no conflict of interest.

\section{Acknowledgments}

The work was supported by the National Natural Science Foundation of China (41471347), donations from Delos Living LLC, and the Cyrus Tang Foundation to Tsinghua University. We thank Ben Wielstra, Yaomin Zheng, Sheng Li, Nils C. Stenseth, and Willem F. de Boer for comments and discussions. Maps in this paper were reviewed by Ministry of Natural Resources of the People's Republic of China (GS(2021)361).

\section{Appendix A. Supplementary materials}

Supplementary materials to this article can be found online at https://doi.org/10.1016/j.scib.2021.01.033.

\section{References}

[1] IUCN. The iucn red list of threatened species. Version 2019-3. 2020, http:// www.iucnredlist.org. Accessed 1 May 2020.

[2] Ma Z, Melville DS, Liu J, et al. Rethinking China's new great wall. Science 2014;346:912-4.

[3] Gong P, Li X, Zhang W. 40-Year (1978-2017) human settlement changes in China reflected by impervious surfaces from satellite remote sensing. Sci Bull 2019;64:756-63.

[4] Niu ZG, Zhang HY, Wang XW, et al. Mapping wetland changes in China between 1978 and 2008. Chin Sci Bull 2012;57:2813-23 (in Chinese).

[5] Murray NJ, Phinn SR, DeWitt M, et al. The global distribution and trajectory of tidal flats. Nature 2019;565:222-5.

[6] Xu Y, Si Y, Takekawa J, et al. A network approach to prioritize conservation efforts for migratory birds. Conserv Biol 2020;34:416-26.

[7] Studds CE, Kendall BE, Murray NJ, et al. Rapid population decline in migratory shorebirds relying on yellow sea tidal mudflats as stopover sites. Nat Commun 2017;8:14895.

[8] Bauer S, Hoye BJ. Migratory animals couple biodiversity and ecosystem functioning worldwide. Science 2014;344:1242552.

[9] BirdLife International, Digital boundaries of Important Bird and Biodiversity Areas from the World Database of Key Biodiversity Areas (March 2019 Version). 2019, http://datazone.birdlife.org/site/requestgis. Accesed 13 December 2019.

[10] MacArthur RH, Wilson EO. The Theory of Island Biogeography. New Jersey: Princeton University Press; 1967.

[11] Saura S, Pascual-Hortal L. A new habitat availability index to integrate connectivity in landscape conservation planning: comparison with existing indices and application to a case study. Landsc Urban Plan 2007;83:91-103. 
[12] Xu H, Cui P, Zhu X, et al. Progress in construction of China bird diversity observation network (China bon-birds). J Ecol Rural Environ 2018;34:1-11.

[13] Ma K. Biodiversity monitoring in China: from CForBio to Sino BON. Biodiv Sci 2015;23:1-2.

[14] Ma Z, Chen Y, Melville DS, et al. Changes in area and number of nature reserves in China. Conserv Biol 2019;33:1066-75.

[15] Seto KC, Guneralp B, Hutyra LR. Global forecasts of urban expansion to 2030 and direct impacts on biodiversity and carbon pools. Proc Natl Acad Sci USA 2012;109:16083-8.

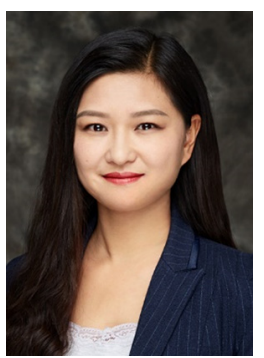

Yali Si is a visiting associate professor of the Department of Earth System Science at Tsinghua University. Her research interest covers global change on bird distribution, diversity, and movement, the environmental mechanisms of disease burden, and biodiversity conservation in human-dominated landscapes.

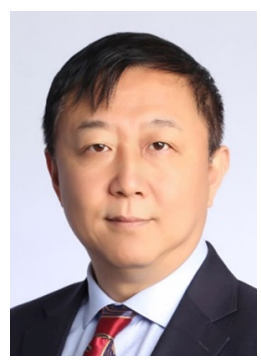

Peng Gong is professor and chair of the Department of Earth System Science, Dean of School of Sciences at Tsinghua University. His major research interest includes mapping and monitoring of global environmental change using satellite and ground-based sensors, monitoring of migratory birds, and modeling of environmentally related infectious diseases. 